\title{
FENOLOGI DAN PERTUMBUHAN STRAWBERRY DI DATARAN RENDAH SEBAGAI KAJIAN AWAL DAMPAK PERUBAHAN IKLIM TERHADAP PERTUMBUHAN TANAMAN
}

\author{
Phenology and Growth of Strawberry in Low Land as Prior Study of \\ the Impact of Climate Change on Plant Growth
}

\author{
Paul B. Timotiwu' ${ }^{1)}$, Tumiar K. Manik ${ }^{1)}$, Agustiansyah ${ }^{1)}$, Eko Pramono ${ }^{1)}$ \\ ${ }^{1}$ Jurusan Agronomi dan Hortikultura Fakultas Pertanian Universitas Lampung \\ Jl. Sumantri Brojonegoro No 1 Gedung Meneng, Bandar Lampung 35145 \\ *E-mail Korespondensi: tumiar.katarina@fp.unila.ac.id
}

\begin{abstract}
ABSTRAK
Seperti telah banyak dipahami, perubahan iklim ditandai dengan kenaikan suhu udara, sehingga seharusnya penelitian pengaruh perubahan iklim terhadap tanaman dimulai dengan mempelajari bagaimana pengaruh kenaikan suhu udara terhadap proses dalam tanaman dan pada produksi, sehingga dapat dikembangkan teknik bagaimana tanaman beradaptasi terhadap perubahan iklim. Cara yang dapat langsung dilakukan di lapang adalah dengan menggunakan perbedaan ketinggian tempat untuk mendapatkan suhu udara yang berbeda. Reaksi tanaman terhadap perubahan suhu dapat dilihat pada fenologi tanaman yang merupakan deskripsi fase tumbuh tanaman dan dapat dikuantifikasikan melalui konsep yang disebut Growing Degree Days (GDD). Tujuan penelitian ini adalah: 1. Mengidentifikasi pengaruh dari perubahan suhu pada tahap fenologi dan produksi tanaman dataran tinggi (strawberi) dan melalui penanaman pada ketinggian tempat yang berbeda dengan kesesuaian tumbuhnya. 2 . Menghitung GDD diakhir tahap pertumbuhan tanaman dan mengevaluasi kemampuan GDD memprediksi fenologi tanaman. Hasil penelitian menunjukkan tanaman dataran tinggi (Strawberry) jika ditanam didataran rendah yang bersuhu lebih tinggi mengalami beberapa hal yang mengganggu pertumbuhan dan perkembangannya. Sampai minggu ke sepuluh bunga belum merata terlihat pada tanaman, begitu juga penutupan kanopi yang hanya mencapai dibawah 20 persen.
\end{abstract}

Kata Kunci: Fenologi, GDD, cuaca, temperatur, kelembaban, pertumbuhan, strawberry

\begin{abstract}
Climate change has been understood from air temperature that constantly rising. Therefore, to study the impact of climate change on crops growth and production should begin with study the impact of air temperature on crops, so that the technique of making crops adapt to the climate change could be developed. Crops reaction on temperature change could be detected from the phenology and quantified with the Growing degree days (GDD). The objective of this research was to identify the impact of temperature change on strawberry phenology and production through cultivating on low land area and calculating the GDD at the end of the planting period. The results showed that Strawberry on low land experienced some difficulties to grow in optimal rate; up to the $10^{\text {th }}$ week plant still did not reach the generative state uniformly and canopy coverage was below 20 percent.
\end{abstract}

Keywords: Phenology, GDD, humidity, strawberry, temperature, weather 


\section{PENDAHULUAN}

Perubahan iklim akibat peningkatan gas rumah kaca pasti mempengaruhi produksi tanaman dan akhirnya ketersediaan pangan. IPCC (International Panel for Climate Change) memproyeksikan kenaikan suhu 1.8 sampai $4^{\circ} \mathrm{C}$ menjelang tahun 2100 (IPCC, 2007). Kenaikan konsentrasi $\mathrm{CO}_{2}$ yang mengakibatkan kenaikan suhu mempengaruhi aspek fungsi, pertumbuhan dan perkembangan tanaman dengan cara berbeda tergantung jenis tanaman dan lokasi geografis. Produksi tanaman diproyeksikan menurun dengan kenaikan suhu $1-2^{\circ} \mathrm{C}$ di wilayah tropis pada musim kering (IPCC, 2007 dalam Chakrabarti et al., 2012).

Pemanasan global mempengaruhi pertumbuhan tanaman salah satunya melalui hambatan fotosintesis dan keragaman biomas. Tanaman juga dapat mengalami kerusakan fisik karena tekanan suhu tinggi, diperkirakan sampai rata rata $17 \%$ penurunan hasil panen untuk tiap kenaikan suhu udara 1 derajat celsius (Lobel and Asner, 2003). Perubahan suhu mempengaruhi ukuran dan berat daun tanaman tropis dan kenaikan suhu mengubah ketergantungan termal dari laju fotosintesis. Pada beberapa spesies, suhu optimal yaitu suhu untuk memaksimalkan laju fotosintesis meningkat dengan naiknya suhu (Garrun, et al., 2014).

Pengaruh perubahan iklim khususnya suhu yang berpengaruh kuat terhadap fisiologis tanaman yang akhirnya mempengaruhi pertumbuhan, dan produksi tanaman belum banyak dilakukan. Tingkat kesulitan yang dialami para peneliti terutama karena rumitnya teknik mengubah suhu udara di lapangan pada hamparan luas. Karena perubahan iklim ditandai dengan kenaikan suhu udara, sehingga seharusnya penelitian pengaruh perubahan iklim terhadap tanaman dimulai dengan mempelajari bagaimana pengaruh kenaikan suhu udara terhadap proses dalam tanaman dan pada produksi, sehingga dapat dikembangkan teknik bagaimana tanaman beradaptasi terhadap perubahan iklim.

Cara yang dapat langsung dilakukan di lapang adalah dengan menggunakan perbedaan ketinggian tempat untuk mendapatkan suhu udara yang berbeda. Dengan perbedaan ketinggian tempat dapat dilihat reaksi tanaman dataran tinggi ketika ditanam di dataran rendah dan sebaliknya tanaman dataran rendah ketika ditanam di dataran tinggi. Reaksi tanaman dapat diteliti melalui apa yang disebut fenologi tanaman. Fenologi adalah ilmu tentang tahap-tahap pertumbuhan dan perkembangan tanaman secara alamiah sebagai tanggapan terhadap iklim atau musim dan lingkungan (Ziello et al., 2009).

Memahami fenologi dapat membantu para ilmuwan memahami perubahan pada tanaman khususnya di daerah lintang tinggi karena pengaruh perubahan iklim dan pengamatan fenologis sekarang menjadi penting dalam mengamati dampak perubahan iklim (Menzel, 2002).Vegetasi bereaksi terhadap perubahan iklim dengan mengubah pola fenologinya seperti: bergesernya waktu pencapaian fase tumbuh tanaman, berpindahnya lokasi tempat tumbuh tanaman karena menyesuaikan dengan suhu udara, berubahnya morfologi, reproduksi atau genetika tanaman atau tanaman akan punah (Workie and Debella, 2018).

Fenologi tanaman yang merupakan deskripsi fase tumbuh tanaman dapat dikuantifikasikan melalui konsep yang disebut Growing Degree Days (GDD). GDD adalah prasyarat untuk membuat model tanaman yaitu pendugaan yang tepat waktu perkembangan tanaman dengan suhu udara yang merupakan regulator utama dari perkembangan (Bewick et al., 1988). Nilai Growing degree day digunakan untuk memprediksi pertumbuhan tanaman (Yang et al., 1995; McMaster and Wilhelm,1997), biasanya dengan cara menjumlahkan nilai suhu harian. Dengan meningkatnya suhu global makin cepat akumulai GDD. Selain suhu fotoperiodisme juga faktor lingkungan 
utama yang menentukan waktu mencapai pembungaan dan munculnya bunga pertama pada tanaman (Daba et al., 2016). Dengan demikian perkembangan tanaman adalah fungsi dari suhu dan panjang hari, keduanya harus disertakan dalam algoritme prediksi (Aslam et al., 2017). Penelitian ini dilakukan untuk memperkirakan bagaimana tumbuhan tanggap terhadap perubahan iklim dan menjadi dasar kebijakan ketersediaan pangan.

Penelitian pengaruh perubahan iklim terhadap tanaman sangat sedikit dilakukan di daerah Tropis, karena dianggap bahwa suhu didaerah Tropis tidak banyak berfluktuasi, tetapi banyak penelitian mengatakan bahwa daerah Tropis akan lebih menderita untuk kenaikan suhu yang kecil sekalipun. Tujuan penelitian ini adalah: (1) Mengidentifikasi pengaruh dari perubahan iklim pada tahap pertumbuhan dan perkembangan tanaman dataran tinggi (Strawberry) melalui penanaman pada ketinggian tempat yang berbeda dengan kesesuaian tumbuhnya; (2) Menghitung GDD pada akhir tahap pertumbuhan tanaman dan mengevaluasi kemampuan GDD memprediksi fenologi tanaman dibandingkan dengan GDD di lokasi lain.

\section{METODE PENELITIAN}

\section{Tempat dan Waktu Penelitian}

Penelitian dilakukan pada lahan di Kecamatan Sukarame, Bandar Lampung (200 m dpl), Bulan Maret sampai pertengahan September 2020.

\section{Penanaman Strawberry}

Penanaman strawberry mengikuti teknik budidaya tanaman yang dilakukan petani dengan pemeliharaan yang optimal mendukung pertumbuhan tanaman, tanpa perlakuan tambahan.

\section{Pengamatan}

Unsur cuaca (suhu dan kelembaban udara harian) yang diukur setiap selang 1 jam dengan menggunakan pengukur suhu dan kelembaban yang disertai data logger (Flush USB humidity and temperature data logger recorder tipe E3845). Dengan data logger, suhu dan kelembaban udara dapat diukur setiap jam. Radiasi matahari dan PAR diukur dengan Skye Instrument with quantum and pyranometer sensors.

Laju pertumbuhan tanaman dan produksi tanaman dilakukan dengan metode destruktif. Setiap minggu dua tanaman dicabut untuk pengukuran panjang dan lebar penutupan tanaman, tinggi tanaman, panjang dan lebar daun, panjang akar, dan bobot segar tanaman. Setelah tanaman dikeringkan dengan menggunakan oven, kemudian ditimbang untuk mendapatkan bobot kering tanaman dan bagian bagiannya (akar, batang dan daun). Pengamatan juga dilakukan dengan membuat foto perkembangan tanaman sebagai data deskriptif.

\section{Pengolahan Data}

Untuk sebagian besar tanaman, perkembangan fenologi sangat berkaitan dengan akumulasi panas atau unit suhu. Suhu batas bawah beragam untuk tiap spesies tanaman. Suhu dasar terendah bagi Strawberry adalah $10^{\circ} \mathrm{C}$ dan tertinggi $26^{\circ} \mathrm{C}$ (Kesici et al., 2013).

Indeks suhu yang paling umum digunakan untuk menduga perkembangan tanaman adalah growing degree days (GDD) yang dihitung dari suhu maksimum dan minimum harian.

\section{HASIL DAN PEMBAHASAN}

\section{Iklim Mikro Lokasi Penanaman}

Secara rata rata radiasi matahari di dataran rendah Sukarame, Bandar Lampung adalah $609,40 \mathrm{watt} / \mathrm{m}^{2}$ dan didalam rumah kaca sebesar $291,61 \mathrm{watt} / \mathrm{m}^{2}$, suhu udara minimum $28,21^{\circ} \mathrm{C}$, maksimum $34,11^{\circ} \mathrm{C}$ dan suhu rata-rata $24,97^{\circ} \mathrm{C}$, suhu tanah $30,74^{\circ} \mathrm{C}$ dan kelembaban 53\%. Tidak ada pengukuran yang kontinyu untuk dataran tinggi (Sekincau) akan tetapi pengukuran 
pada bulan Januari 2020 menunjukkan bahwa rata rata intensitas radiasi pada siang hari adalah $186,99 \mathrm{watt} / \mathrm{m}^{2}$, suhu udara siang hari 27,00 dan kelembaban $71,91 \%$. Perbandingan ini menunjukkan iklim mikro lokasi penelitian yang berada di dataran rendah berada di luar suhu optimal pertumbuhan strawberry yaitu $10-26^{\circ} \mathrm{C}$ (Kesici et al., 2013)(Gambar 1).

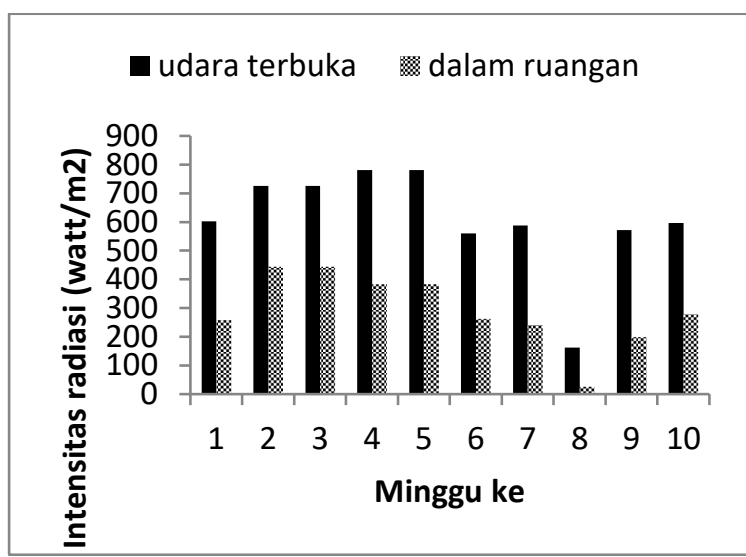

Gambar 1. Intensitas radiasi dataran rendah di udara terbuka dan dalam ruangan

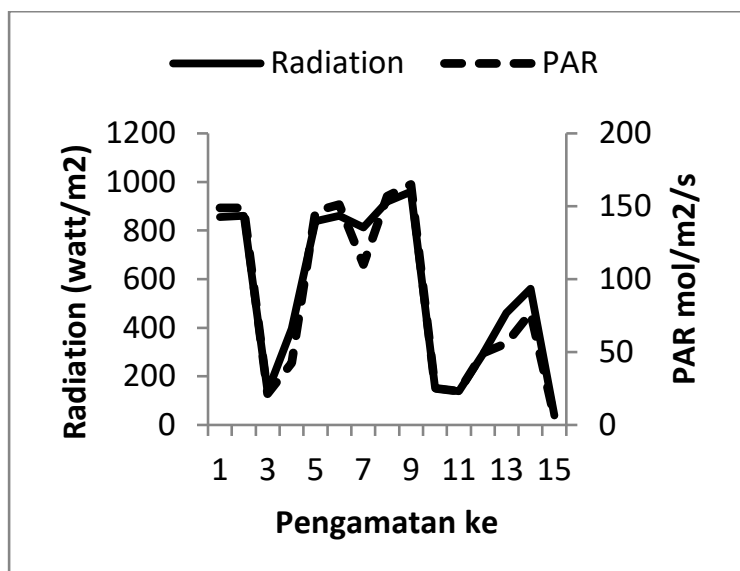

Gambar 2. Perbandingan kuantitas radiasi matahari dengan Photoshyntesis Active Radiation (PAR)

Radiasi matahari di dalam ruangan tetap lebih tinggi daripada radiasi di tempat terbuka di dataran tinggi. Tidak semua radiasi dapat dimanfaatkan oleh tanaman, bagian radiasi yang digunakan oleh tanaman disebut Photoshyntesis Active Radiation (PAR). Dari pengukuran baik di udara terbuka maupun di dalam ruangan (Gambar
2), rata-rata PAR secara umum adalah 12$17 \%$ dari jumlah radiasi.

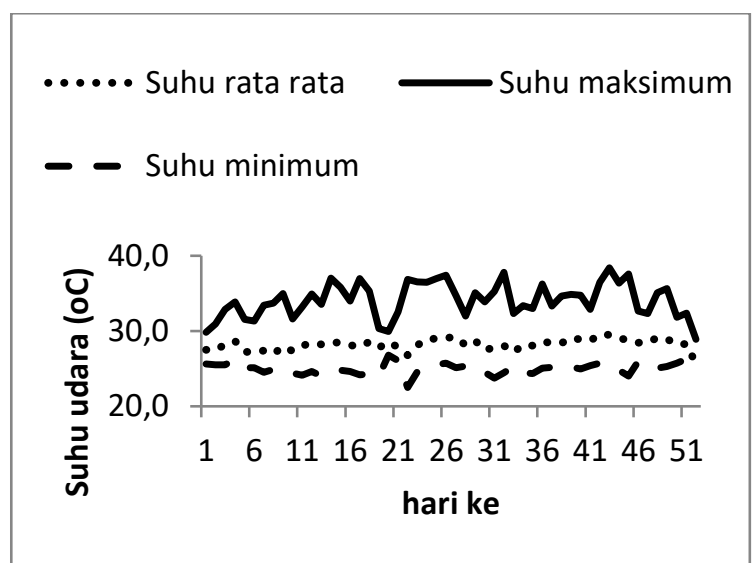

Gambar 3. Suhu udara harian maksimum, minimum dan rata rata

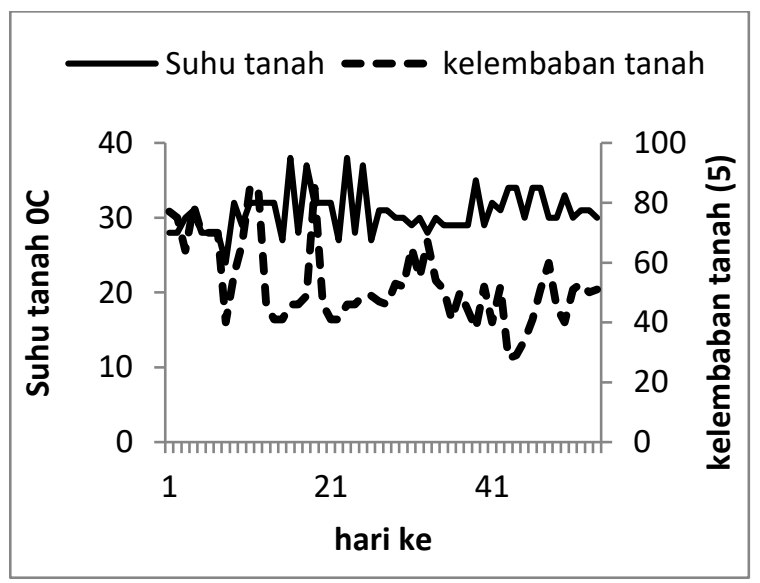

Gambar 4. Suhu dan kelembaban tanah harian

\section{Pertumbuhan dan perkembangan tanaman}

Analisa pertumbuhan digunakan secara luas sebagai alat penelitian dari mulai pemuliaan tanaman, fisiologi tumbuhan sampai ekologi tanaman. Analisa pertumbuhan mewakili langkah pertama dalam analisa produktivitas sehingga merupakan penghubung penting antara mengukur hasil tanaman dan memahami fenomena fisiologis yang menentukan hasil. Dalam penelitian analisis pertumbuhan meliputi jumlah dan luas daun, panjang tanaman (akar-pucuk), panjang batang, panjang akar, rasio akar batang dan rasio berat luas daun (Gambar 5 - 10). 


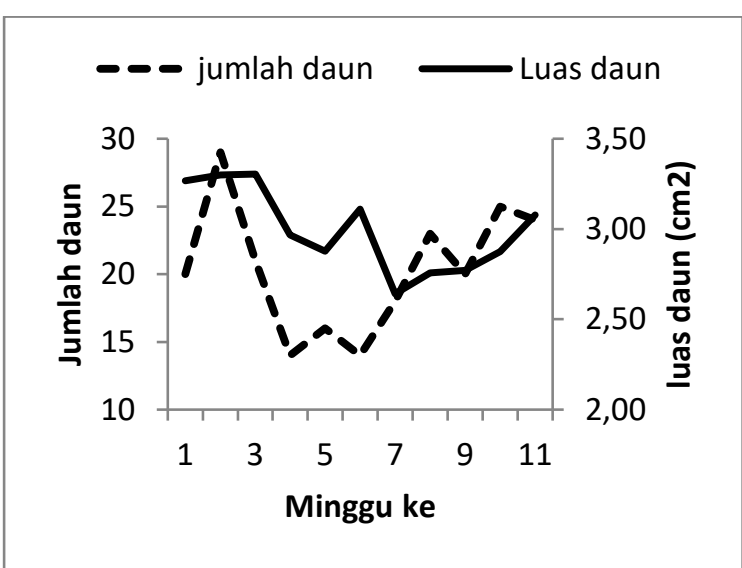

Gambar 5. Jumlah dan luas daun strawberry ditanam di dataran rendah

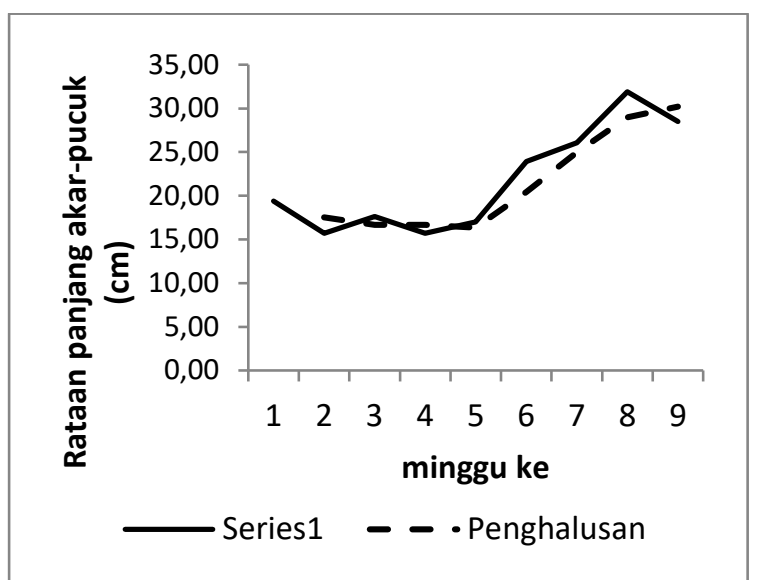

Gambar 6. Rataan panjang akar sampai pucuk tanaman Strawberry di dataran rendah

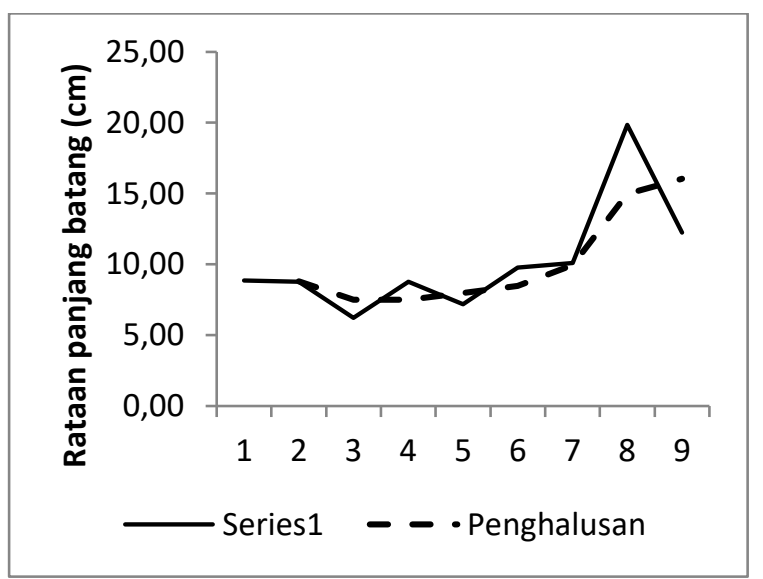

Gambar 7. Rataan panjang batang tanaman Strawberry di dataran rendah

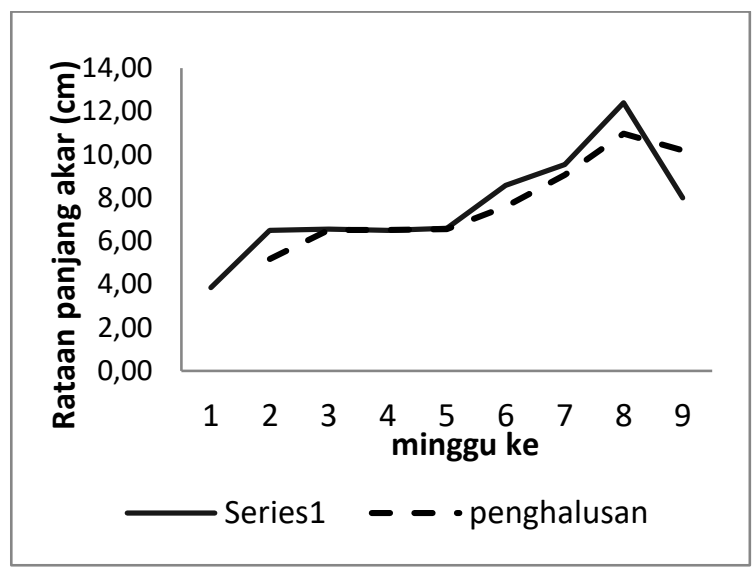

Gambar 8. Rataan panjang akar tanaman Strawberry di dataran rendah

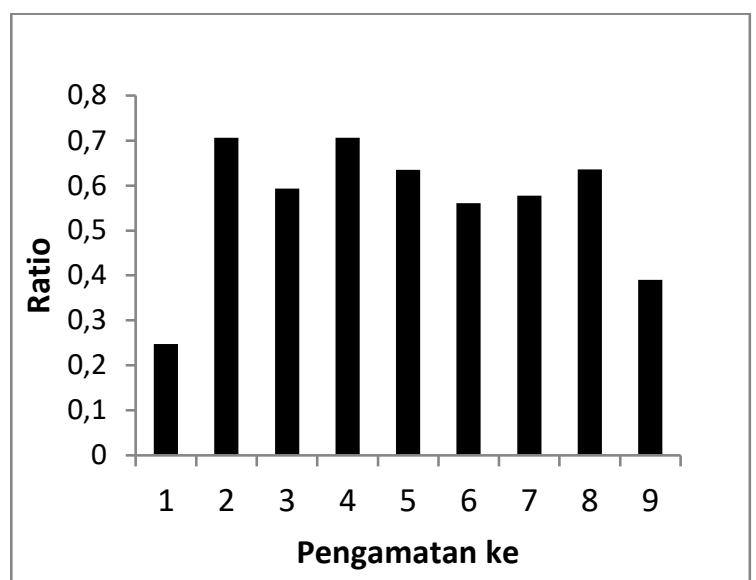

Gambar 9. Rasio akar dan batang Strawberry di dataran rendah

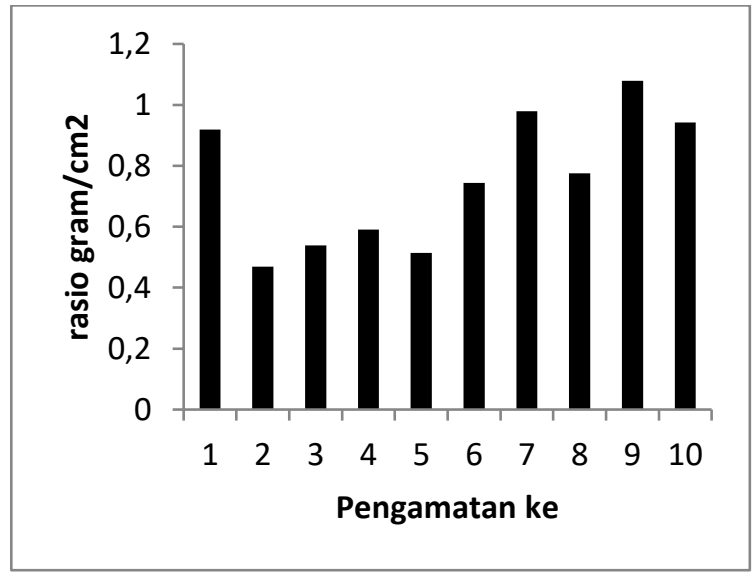

Gambar 10. Rasio berat daun (gram) terhadap luas daun $(\mathrm{cm} 2)$ 


\section{Pengaruh Iklim Mikro Penanaman Strawberry di Dataran Rendah}

Iklim mikro tanaman di lokasi penelitian ini berada di luar iklim mikro dari habitat strawberry. Di Southwestern Coast of Spain $\left(37^{0} \mathrm{LU}\right)$ strawberry ditanam di daerah bersuhu $13,4^{\circ} \mathrm{C}$ dan radiasi 14,3 $\mathrm{MJ} / \mathrm{m}^{2}$; di Tunja, Colombia suhu rata rata $15,8^{\circ} \mathrm{C}$ dengan kelembaban relatif $72 \%$. Sedangkan di Bandar Lampung radiasi matahari adalah 609,40 watt $/ \mathrm{m}^{2}$ dan di dalam rumah kaca sebesar 291,61 watt $/ \mathrm{m}^{2}$ dan suhu rata rata $24,97^{\circ} \mathrm{C}$.

Berdasarkan pada pengamatan pada data yang berkaitan dengan suhu, tahap pertumbuhan dan perkembangan strawberry, ditemukan bahwa yang paling dipengaruhi adalah tahap vegetatif. Juga diamati bahwa periode antara transplantasi sampai awal pembungaan yaitu sekitar satu bulan sebelum panen, yang terbaik adalah tanaman berada pada suhu kurang dari $15^{\circ} \mathrm{C}$ (Da Costa et al., 2017). Hal ini terlihat dari penelitian ini dimana pertumbuhan vegetatif tidak menampakkan pertumbuhan yang cepat, setiap minggu. Rata rata pertumbuhan baru terjadi setelah minggu ke 6, karena iklim mikro tanaman di lokasi penelitian ini berada di luar selang suhu habitat penanaman strawberry.

Fenologi tanaman yang merupakan deskripsi fase tumbuh tanaman dapat dikuantifikasikan melalui konsep yang disebut Growing Degree Days (GDD). GDD adalah hubungan antara suhu udara dengan laju pertumbuhan tanaman; sebuah hubungan yang linier yang berasumsi bahwa laju pertumbuhan tanaman proporsional dengan suhu udara. GDD juga dapat digunakan untuk memprediksi umur tanaman sehingga waktu panen tidak lagi hanya berdasarkan hari setelah tanam tetapi memperhitungkan faktor cuaca. Di negara negara Baltik, Strawberry mulai berbunga dengan jumlah growing degree days 586, panen pertama 870 dan kedua 965 (Bethere et al., 2016). Tetapi kelihatannya hal ini perlu diteliti lagi karena hasilnya tidak seperti yang dikatakan dalam teori; sampai tanggal 29 Agustus 2020 (45 hari) jumlah GDD adalah 1117, 7 unit dan sampai minggu ke sepuluh tanaman strawberry belum berbuah.

Tabel 1. Growing degree days Strawberry di dataran rendah

\begin{tabular}{|c|c|c|c|}
\hline $\begin{array}{l}\text { Peng- } \\
\text { amatan } \\
\text { ke }\end{array}$ & Tanggal & GDD & $\begin{array}{c}\text { Fase } \\
\text { tumbuh }\end{array}$ \\
\hline 1 & 25 Juli 2020 & 247,45 & Vegetatif \\
\hline 2 & $\begin{array}{l}1 \text { Agustus } \\
2020\end{array}$ & 425,05 & Vegetatif \\
\hline 3 & $\begin{array}{l}\text { 8Agustus } \\
2020\end{array}$ & 594,7 & Vegetatif \\
\hline 4 & $\begin{array}{l}15 \text { Agustus } \\
2020\end{array}$ & 770,8 & Vegetatif \\
\hline 5 & $\begin{array}{l}22 \text { Agustus } \\
2020\end{array}$ & 938,55 & Vegetatif \\
\hline 6 & $\begin{array}{l}29 \text { Agustus } \\
2020\end{array}$ & 1117,7 & Vegetatif \\
\hline
\end{tabular}

Dari luasnya batasan dari faktor yang mempengaruhi penampilan tanaman dan potensi panen dari strawberry (Fragaria $\mathrm{x}$ ananassa Duch.), suhu dan panjang hari yang dipengaruhi lintang adalah yang paling penting. Selain foto period interaksi yang kuat antara suhu dan panjang hari menentukan transisi fari vegetatif ke pembungaan yang bervariasi anta kultivar (Kruger et al., 2012). Antesis semakin mundur dari lintang selatan ke utara yang menggambarkan pengaruh lintang yaitu karena menurunnya suhu dari selatan ke utara. anthesis secara umum berkaitan dengan suhu dari minggu-minggu sebelumnya.

Secara umum lamanya pembentukan buah berbanding terbalik terhadap suhu rata rata harian yang berarti semakin lama dengan kenaikan lintang. Di berbagai tempat penelitian kira-kira dibutuhkan 27-38 hari dari antesis ke awal panen. Semua kultivar membutuhkan waktu yang lebih lama di tahun dengan suhu yang lebih rendah dibandingkan tahun dengan suhu lebih tinggi. Sebuah evaluasi yang dilakukan dengan tiga kultivar strawberry pada 5 lokasi 
yang mencangkup 20 derajat lintang di Eropa. Pembentukan buah dari antesis ke awal panen, lamanya musim panen, kualitas buah internal dan eksternal dipelajari dalam kaitannya dengan suhu, PAR dan GDD. Hasilnya menunjukkan, GDD yang dihitung untuk setiap tingkatan fenologi membutuhkan lebih banyak informasi tentang suhu dasar, optimum dan kritis pada tahap fenologi yang berbeda. Hasil dari kualitas buah menunjukkan pengaruh lintang yaitu semakin rendah suhu makin tinggi berat kering, padatan yang dikonsumsi dan titrasi kemasaman, juga semakin rendah suhu semakin merah warna buah.

\section{KESIMPULAN}

(1) Tanaman dataran tinggi (Strawberry) jika ditanam di dataran rendah yang bersuhu lebih tinggi mengalami beberapa hal yang mengganggu pertumbuhan dan perkembangannya antara lain perkembangan vegetatif yang terhambat, laju pertumbuhan hampir sama saja setiap minggu, beberapa daun sudah mengering sehingga jumlah daun berkurang. Sampai minggu ke sepuluh bunga belum merata terlihat pada tanaman, begitu juga penutupan kanopi yang hanya mencapai di bawah 20 persen.

(2) Jika suhu udara cenderung meningkat karena perubahan iklim dikuatirkan akan banyak areal penanaman yang bergerak menempati lokasi yang lebih tinggi, sehingga areal pegunungan akan rentan terhadap pembukaan lahan yang dalam jangka panjang berbahaya bagi lingkungan.

(3) Secara teori semakin tinggi suhu maka fase perkembangan tanaman akan lebih cepat. Tetapi dalam penelitian ini tidak terlihat seperti dalam teori. Diperlukan penelitian lanjutan tentang suhu dasar, suhu optimum dan maksimum tanaman sehingga penghitungan Growing Degree Days lebih akurat.

\section{DAFTAR PUSTAKA}

Aslam, M. A., M. Ahmed, C. O. Stöckle, S. S. Higgins, F. ul Hassan and R. Hayat. 2017. Can Growing Degree Days and Photoperiod Predict Spring Wheat Phenology? Frontiers in Environmental Science, 5(57). doi: 10.3389/fenvs.2017.00057.

Bewick, T. A., L. K. Binning, and B.Yandell. 1988. A degree-day model for predicting the emergence of swamp dodder in cranberry. J. Am. Soc. Hort. Sci. 113, 839841.

Bethere, L., T. Sīle, J. Seņnikovs and U. Bethers. 2016. Impact of climate change on the timing of strawberry phonological processes in the Baltic States. Estonian Journal of Earth Sciences, 65(1): 48-58. doi:10.3176/earth.2016.04.

Chakrabarti, B., S. D. Singh, V. Kumar, R. C. Harit, and S. Misra. 2013. Growth and yield response of wheat and chickpea crops under high temperature. Ind $J$ Plant Physiol, 18(1): 7-14. DOI 10.1007/s40502-0130002-6.

Da Costa, R. C., E. O. Calvete, J. L. T. Chiomento, N. Dos S. Trentin, F. S. De Nardi. 2016. Vegetative Stage Of Strawberry Duration Determined By The Crop Year. Rev. Bras. Frutic. 39(5): (1-7). doi: 10.1590/0100-29452017 831.

Daba, K., T. D.Warkentin, R. Bueckert, C. D. Todd and B.Tar'an. 2016. Determination of photoperiod- sensitive phase in chickpea (Cicer arietinumL.). Front. Plant Sci. 11:478. doi: 10.3389/fpls.2016.00478.

Garruna-Hernandez, R., R. Orellana, A. LarqueSaavedra, and A. Canto. 2014. Understanding the Physiological Responses of a Tropical Crop (Capsicum chinense Jacq.) at High Temperature. PLoS ONE 9(11): e111402. doi: 10.1371 /journal/pone.0111402.

IPCC. 2007. The synthesis report of the Intergovernmental Panel on climate change. Cambridge: Cambridge University Press. 
Kesici, M., H. Gulen, S. Ergin, E. Turhan, A. Ipek, and N. Koksal. 2013. Heat-stress Tolerance of Some Strawberry (Fragaria $\times$ ananassa) Cultivars. Not Bot Horti Agrobo, 41(1):244-249.

Kruger, E., M. Josuttisa, R. Nestby, T.B. Toldam-Andersen, C. Carlen and B. Mezzetti. 2012. Influence of growing conditions at different latitudes of Europe on strawberry growth performance, yield and quality. Journal of Berry Research, 2: 143-157. doi:10.3233/JBR-2012-036.

Lobell, D.B. and G.P. Asner. 2003. Climate and management contributions to recent trends in U.S. agricultural yields. Science, 299: 1032.

McMaster, S. G. and W. W. Wilhelm .1997. Growing degree-days: one equation, two interpretations. Agric. Forest Meteor, 87: 291-300. doi: 10.1016/S01681923(97)00027-0.
Menzel, A. 2002. Phenology: its importance to the global change community. Clim Change, 54:379-385.

Workie, T. G. and H. J. Debella. 2018. Climate change and its effects on vegetation phenology across ecoregions of Ethiopia. Global Ecology and Conservation, 13. https://doi.org/10.1016/j.gecco.2017.e0036 6.

Yang, S., J. Logan, and D. L Coffey. 1995. Mathematical formulae for calculating the base temperature for growing degree days. Agric. Forest Meteor. 74: 61-74. doi: 10.1016/0168-1923(94)02185-M.

Ziello, C., N. Estrella and M. Kostova. 2009. Influence of altitude on phenology of selected plant species in the alpine region (1971- 2000). Climate Res. 39: 227-234. doi:10.3354/cr00822. 